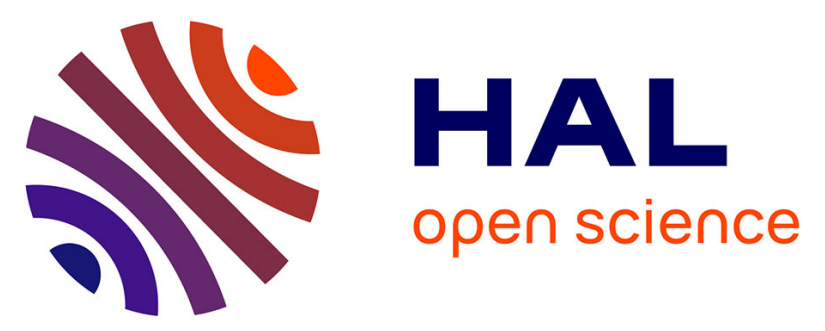

\title{
Improved promoter effect in NiWS catalysts through a molecular approach and an optimized $\mathrm{Ni}$ edge decoration
}

Thibault Alphazan, Audrey Bonduelle-Skrzypczak, Christèle Legens, Zoubeyr

Boudene, Anne-Lise Taleb, Anne-Sophie Gay, Ovidiu Ersen, Christophe

Copéret, Pascal Raybaud

\section{To cite this version:}

Thibault Alphazan, Audrey Bonduelle-Skrzypczak, Christèle Legens, Zoubeyr Boudene, Anne-Lise Taleb, et al.. Improved promoter effect in NiWS catalysts through a molecular approach and an optimized Ni edge decoration. Journal of Catalysis, 2016, 340, pp.60-65. 10.1016/j.jcat.2016.05.004 . hal-01449790

\author{
HAL Id: hal-01449790 \\ https://hal.science/hal-01449790
}

Submitted on 2 Feb 2017

HAL is a multi-disciplinary open access archive for the deposit and dissemination of scientific research documents, whether they are published or not. The documents may come from teaching and research institutions in France or abroad, or from public or private research centers.
L'archive ouverte pluridisciplinaire HAL, est destinée au dépôt et à la diffusion de documents scientifiques de niveau recherche, publiés ou non, émanant des établissements d'enseignement et de recherche français ou étrangers, des laboratoires publics ou privés. 


\section{Improved promoter effect in NiWS catalysts through a molecular approach and an optimized Ni edge decoration}

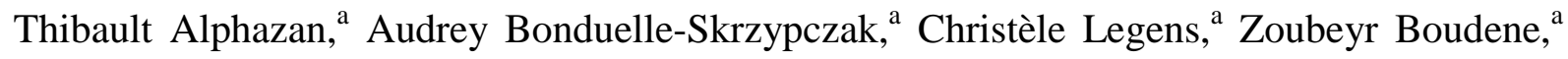
Anne-Lise Taleb, ${ }^{\mathrm{a}}$ Anne-Sophie Gay, ${ }^{\mathrm{a}}$ Ovidiu Ersen, ${ }^{\mathrm{b}}$ Christophe Copéret, ${ }^{\mathrm{c},{ }^{*}}$ Pascal Raybaud, ${ }^{\mathrm{a}, *}$

${ }^{\text {a }}$ IFP Energies nouvelles, Rond-point de l'échangeur de Solaize, 69360 Solaize, France.

b IPCMS-UMR 7504 CNRS-Université de Strasbourg, 23 rue du Loess BP 43-67034 Strasbourg cedex 2 (France)

${ }^{c}$ ETH Zürich, Department of Chemistry and Applied Biosciences, Vladimir Prelog Weg. 1-5, CH-8093 Zürich, Switzerland

\section{Corresponding Authors:}

Pascal Raybaud, IFP Energies nouvelles, email : pascal.raybaud@ifpen.fr

Christophe Copéret, ETH Zürich, email : ccoperet@inorg.chem.ethz.ch 


\begin{abstract}
An efficient preparation method - based on the grafting and deposition of $\mathrm{Ni}$ and $\mathrm{W}$ molecular precursors onto partially dehydroxylated amorphous silica-alumina followed by a thermal treatment under $\mathrm{H}_{2} \mathrm{~S} / \mathrm{H}_{2}$ - generates supported NiWS catalysts exhibiting enhanced activities in toluene hydrogenation, by comparison with conventional samples, prepared from metallic salts. A careful analysis of these materials by IR, XPS, TEM, HAADF-STEM, together with DFT calculations, reveals that the improved activity probably originates from the lower sulfidation temperature of $\mathrm{W}$ that improves distribution of $\mathrm{Ni}-\mathrm{W}$ mixed sites at the edges of NiWS crystallites, thus providing an optimal compromise between intrinsic activity and surface concentration of active sites.
\end{abstract}

Keywords: hydrotreatment, toluene hydrogenation, NiWS, surface chemistry, mixed edge sites, 


\section{Introduction}

In the context of the evolution of oil resources and environmental regulations, the expected expansion of catalytic hydrocracking and hydrotreating (HDT) processes for producing clean - sulfur free - fuels remains a crucial industrial challenge. Promoted molybdenum and tungsten phases (CoMoS, NiMoS, NiWS) are profitably used in industrial HDT processes.[1] Despite intense research in this area, a strong challenge resides in the continuous improvement of the intrinsic catalytic performance of these active phases, and more particularly for $\mathrm{WS}_{2}$ based catalysts.

Recently, the preparation of HDT catalysts through a molecular approach[2] referred to as surface organometallic chemistry (SOMC) or in a more general term controlled surface chemistry (CSC)[3-7] allowed reaching high catalytic performances for non-promoted $\mathrm{WS}_{2}$ phases supported on amorphous silica-alumina (ASA). In particular, the sulfide phase generated by CSC exhibits specific two-dimensional (2D) morphology features and unprecedented sulfidation level, even at temperatures as low as $23^{\circ} \mathrm{C}$.[2] However CSC nonpromoted $\mathrm{WS}_{2}$ catalysts remain much less active than their conventional $\mathrm{Ni}(\mathrm{Co})$-promoted counterparts prepared from metallic salts in aqueous solution, which exhibit higher intrinsic hydrodesulfurization (HDS) or hydrogenation (HYD) activities by at least one order of magnitude.[1] In the early eighties, silica and alumina supported NiMoS and NiWS phases were prepared by a similar CSC approach, and revealed enhanced activity in thiophene HDS, by comparison with catalysts prepared with conventional $\mathrm{Ni}$ and $\mathrm{W}$ salts in aqueous solution.[8] Whatever the preparation method, it is expected that the fine tuning of the promoter $(\mathrm{Ni}, \mathrm{Co})$ to metal $(\mathrm{W}, \mathrm{Mo})$ ratio should provide optimized activities.[8-12] According to density functional theory (DFT) studies,[10,13,14] modifying the 
promoter/Mo(W) ratio provides various structural configurations of the active sites located at the "M-edge" or "S-edge" of the NiMoS or NiWS nanocrystallites. However, quantitative structure-activity relationship between the $\mathrm{Ni}$ promoter edge location in each $\mathrm{NiW}(\mathrm{Mo}) \mathrm{S}$ nano-crystallite and the resulting intrinsic activity is still a challenging task. It is in particular difficult to tune the Ni/W ratio without modifying simultaneously other parameters such as particle sizes or stacking number.[15] In addition, such structure-activity relationships depend on the targeted reaction: HDS, HYD, hydrodenitrogenation (HDN), etc. Theoretical studies suggested that HYD or HDS active sites for $\mathrm{MoS}_{2}$-based catalysts are located on M- or Sedge.[10,13,14,16] NiWS catalysts, however particularly efficient for reactions involving aromatic hydrogenation (including HDN), $[17,18]$ remain far less studied at a molecular scale than their NiMoS homologues,[19] and their intrinsic performances, still far from being optimal, thus remain to be improved.

In what follows, we use a molecular approach to prepare a broad range of silica-alumina supported NiWS catalysts, where the Ni promoter distribution on $\mathrm{WS}_{2}$ nanocrystallite edges is precisely quantified by various techniques: XPS, TEM, HAADF-STEM and DFT. In particular, we show that well-defined silica-alumina supported NiWS catalysts prepared by a molecular (CSC) approach display enhanced catalytic performances in toluene hydrogenation through a better control of the Ni promoter edge distribution.

\section{Results and Discussion}

ASA-supported NiWS catalysts were prepared by post-treating the ASA-supported $\left[\mathrm{W}(\mathrm{OEt})_{5}\right]_{2}$-based material, prepared by deposition of $\left[\mathrm{W}(\mathrm{OEt})_{5}\right]_{2}$ on ASA,[2] with a toluene solution of $\mathrm{Ni}(\mathrm{acac})_{2}$ through an incipient wetness impregnation (IWI), yielding samples with about $1.6( \pm 0.1)$ W.nm ${ }^{-2}$ and $\mathrm{Ni} / \mathrm{W}$ atomic ratio ranging from 0.21 to 1.00 (Supporting 
Information). After activation through sulfidation, the catalytic performances were evaluated in toluene hydrogenation (see supplementary materials), and all activities $\left(\mathrm{r}_{\mathrm{i}}\right)$ were firstly normalized per total atom of $\mathrm{W}$ (Figure 1). It is one of the goals of the present work to evaluate turnover frequency (TOF) according to the atomic scale description of the active phase and sites as detailed in what follows.

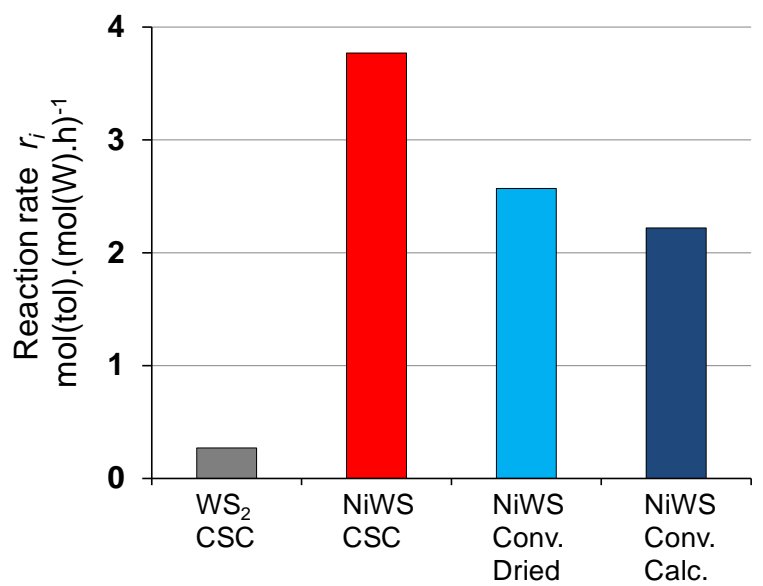

Fig. 1 Reaction rates, expressed in molecule of toluene converted normalized per total atom of W for ASAsupported $\mathrm{WS}_{2}$ and NiWS catalysts, with W coverage ranging from 1.6 to $1.8 \mathrm{~W} . \mathrm{nm}^{-2}$, and Ni/W atomic ratio of $\sim 0.2$. Catalysts underwent sulfidation at $350^{\circ} \mathrm{C}$, under $\mathrm{H}_{2} \mathrm{~S} / \mathrm{H}_{2}$ mixture with $15 \mathrm{~mol} \% \mathrm{H}_{2} \mathrm{~S}$ for $2 \mathrm{~h}$.

Ni-promoted $\mathrm{WS}_{2}$ materials (with $\mathrm{Ni} / \mathrm{W} 0.2$ ) exhibit improved reaction rates, which are one order of magnitude greater than for their non-promoted counterpart. This highlights the "synergy effect" between $\mathrm{W}$ and Ni when engaged in a mixed NiWS phase,[1] similarly to what is known for Co(Ni)MoS phases.[20] More strikingly, NiWS catalysts prepared by CSC are $~ 1.5$ times more active than dried or calcined samples synthesized from metallic salts according to conventional approaches, whether dried or calcined (Supporting Information). Catalytic performances expressed per catalyst weight (Figure S1) illustrate this trend, and highlight the beneficial effect provided by the present molecular approach vs. conventional approaches. 
To evaluate the influence of the different preparation methods on the physico-chemical properties of NiWS phases, samples were first characterized by XPS. For Ni/W ratio of $\sim 0.2$, $\mathrm{WS}_{2}$ catalysts exhibit close levels of sulfidation around 71-73 rel\% $\mathrm{WS}_{2}$, for samples prepared via CSC or by the conventional method using dried samples. The calcined sample undergoes sulfidation to a lesser extent (56 rel\%), which is related to the formation of a refractory tungsten oxide phase during the calcination step. This incomplete sulfidation of W observed for all catalysts, for an industrially relevant sulfidation temperature $\left(350^{\circ} \mathrm{C}\right)$ is consistent with previous studies of ASA [21] or alumina[22-25] supported NiWS catalysts. However, CSC catalysts exhibit high levels of promotion, with up to 80 rel\% NiWS (expressed in relative amount of Ni present in the NiWS phase, Table S1) vs. 57 rel\% and 66 rel\% for calcined and dried samples respectively. The effective amount of NiWS active phase found on the CSC catalyst appears to be similar to the dried sample but higher than the calcined one (Table S1). Note also that for CSC samples, two higher $\mathrm{Ni} / \mathrm{W}$ ratios $(0.44$ and 1.00$)$ were studied. Results show that their amount of $\mathrm{Ni}_{\mathrm{x}} \mathrm{S}_{\mathrm{y}}$ and NiWS phases increase, and that the $(\mathrm{Ni} / \mathrm{W})_{\text {slab }}$ ratio (i.e. $\mathrm{Ni} / \mathrm{W}$ ratio in NiWS slabs) reaches $0.50-0.57$. XPS analyses thus show that the CSC method can efficiently generate Ni promoted $\mathrm{WS}_{2}$ nano-crystallites.

In our previous work,[2] we have shown the ability of surface W ethoxy species to be sulfided at low temperature $\left(23^{\circ} \mathrm{C}\right)$. Therefore, the CSC NiW material was sulfided at $23^{\circ} \mathrm{C}$ in order to get further insights into the genesis of the $\mathrm{Ni}_{\mathrm{x}} \mathrm{S}_{\mathrm{y}}$, NiWS and $\mathrm{WS}_{2}$ phases. XPS analyses (Table S2) highlights first that at ambient temperature, the major part of $\mathrm{Ni}$ is sulfided as a $\mathrm{Ni}_{\mathrm{x}} \mathrm{S}_{\mathrm{y}}$ phase (81 rel\%), with no detectable incorporation of $\mathrm{Ni}$ in $\mathrm{WS}_{2}$ slabs as in the so-called mixed NiWS phase. At $350^{\circ} \mathrm{C}$ however, 80 rel\% of $\mathrm{Ni}$ atoms are incorporated in $\mathrm{WS}_{2}$. The high amount of $\mathrm{W}$ sulfide (42 rel\%) initially generated at $23^{\circ} \mathrm{C}$ on CSC samples probably allows 
for a better promotion of $\mathrm{WS}_{2}$ slabs during sulfidation from $23^{\circ} \mathrm{C}$ to $350^{\circ} \mathrm{C}$. Moreover, the mobility of $\mathrm{Ni}_{\mathrm{x}} \mathrm{S}_{\mathrm{y}}$ species - the Hüttig temperature[26] of $\mathrm{Ni}_{3} \mathrm{~S}_{2}$ is about $260^{\circ} \mathrm{C}$ - enhances the incorporation of $\mathrm{Ni}$ in the $\mathrm{WS}_{2}$ phase being simultaneously formed at lower temperature than through conventional methods. In conventional catalysts, which exhibit no W sulfide phase at $23^{\circ} \mathrm{C}$ under similar conditions,[2,27] incorporation of $\mathrm{Ni}$ in $\mathrm{WS}_{2}$ slabs is likely delayed, and provides lower promotion levels (\%NiWS), in particular for calcined samples.[23] These different genesis processes of NiWS also impact the Ni distribution at the crystallites' edges as it will be discussed with the help of DFT calculations (vide infra). Additional NiWS phases were also prepared by deposition of the $\mathrm{Ni}(\mathrm{acac})_{2}$ onto preformed $\mathrm{WS}_{2}$ (after sulfidation of $\left[\mathrm{W}(\mathrm{OEt})_{5}\right]_{2}$ at $\left.350^{\circ} \mathrm{C}\right)$, as previously proposed in the literature.[8,28-30] XPS analyses and catalytic tests reveal that these catalysts exhibit lower amount of NiWS phase (45 rel\% vs. 80 rel\%) and lower catalytic activity (31\% vs. $67 \%$ of toluene converted) than when prepared using successive impregnation of $\mathrm{W}$ and $\mathrm{Ni}$ molecular precursors, in spite of a high sulfidation level $\left(84 \% \mathrm{WS}_{2}\right)$. When $\mathrm{WS}_{2}$ is preformed at $23^{\circ} \mathrm{C}$ instead of $350^{\circ} \mathrm{C}$, higher amount of NiWS (53\%) and catalytic activity (58\% of toluene converted) are observed. Although more dedicated in-situ characterization analysis of the sulfidation process is required to precisely determine the origin of this improvement, we suspect that it may arise from a better interaction of $\mathrm{Ni}(\mathrm{acac})_{2}$ either with the "nascent" $\mathrm{WS}_{2}$ or with the $\mathrm{W}$ molecular precursor than the preformed $\mathrm{WS}_{2}$.

Interaction between the promoter and $\mathrm{W}$ thus appears to be of paramount importance in the genesis of the active phase, and the role of $\mathrm{W}$ surface species was further investigated. An additional NiWS catalyst was prepared by the successive IWI of a polyoxotungstate precursor and $\mathrm{Ni}(\mathrm{acac})_{2}$. After sulfidation, this NiWS catalyst exhibits lower amount of NiWS phase (7 rel\%) and lower catalytic activity (28\% of toluene converted) than the sample prepared from 
[W(OEt) $]_{2}$ (vide supra). This clearly highlights that previous enhancements provided by the CSC method are linked to the highly reactive $\mathrm{W}$ ethoxy precursor. In this peculiar case, IR and GC/MS analyses (Supporting Information) performed on $\mathrm{Ni}(\mathrm{W})$ materials and the liquid phase after deposition, respectively, suggest a release of acac ligands from the Ni coordination sphere, and their reaction with reactive groups of the ASA support (as proposed for similar complexes deposited onto $\mathrm{Al}_{2} \mathrm{O}_{3}[31]$ or $\mathrm{SiO}_{2}[32]$ ) or surface $\mathrm{W}$-ethoxy species. Overall, the formation of surface species containing both $\mathrm{Ni}$ and $\mathrm{W}$ would favour a more intimate contact between them during sulfide formation, which could explain the higher catalytic performances of CSC catalysts.

TEM analyses were then performed on CSC and conventional catalysts prepared with $\mathrm{Ni}(\text { acac })_{2}$ and $\mathrm{Ni}\left(\mathrm{NO}_{3}\right)_{2}$, respectively (Table S3). The mean length (L) and the mean stacking number $(\mathrm{N})$ of NiWS crystallites are very similar whatever the preparation method: $\mathrm{L}$ 3.5-3.7 and $\mathrm{N}$ 3.1, for Ni/W 0.21-0.22. These characteristics are also similar to those of nonpromoted $\mathrm{WS}_{2}$ crystallites.[2] Worthy of note increasing the Ni/W ratio in CSC catalysts slightly decreases the crystallites size from 3.7 to $3.3 \mathrm{~nm}$, which can be regarded as an indirect signature of the presence of $\mathrm{Ni}$ at edge reducing the edge energy and stabilizing crystallites with higher edge/basal ratio. Overall, the size and stacking (directly related to dispersion) of NiWS slabs are not varying significantly enough to explain the observed differences in activity, for samples with $\mathrm{Ni} / \mathrm{W} \sim 0.2$ (at least).

To investigate 2D-morphology effects originating from the preparation method, HR-HAADFSTEM analyses were undertaken on CSC NiWS nanocrystallites (Ni/W 0.2) found on materials with low (0.5 W.nm ${ }^{-2}$, Figure S6) to medium (1.7 W.nm $\left.{ }^{-2}\right)$ W surface density. Figures 2a and 2b show that the 2D morphologies of CSC crystallites oriented planar to the surface are close to hexagonal shapes. Similar shapes have been observed on conventional 
catalysts,[33] which suggests that the 2D-morphology of NiWS crystallites does not strongly depend on the preparation method for the promoted catalysts. In contrast, 2D morphologies of crystallites observed on non-promoted $\mathrm{WS}_{2}$ catalysts were much more sensitive to the preparation method,[2] while the presence of the Ni promoter does not seem to impact the final 2D morphology. So far, the data suggest that catalytic activities of the CSC and conventional dried samples do not depend on the sulfidation degree, crystallites sizes or 2D shapes.
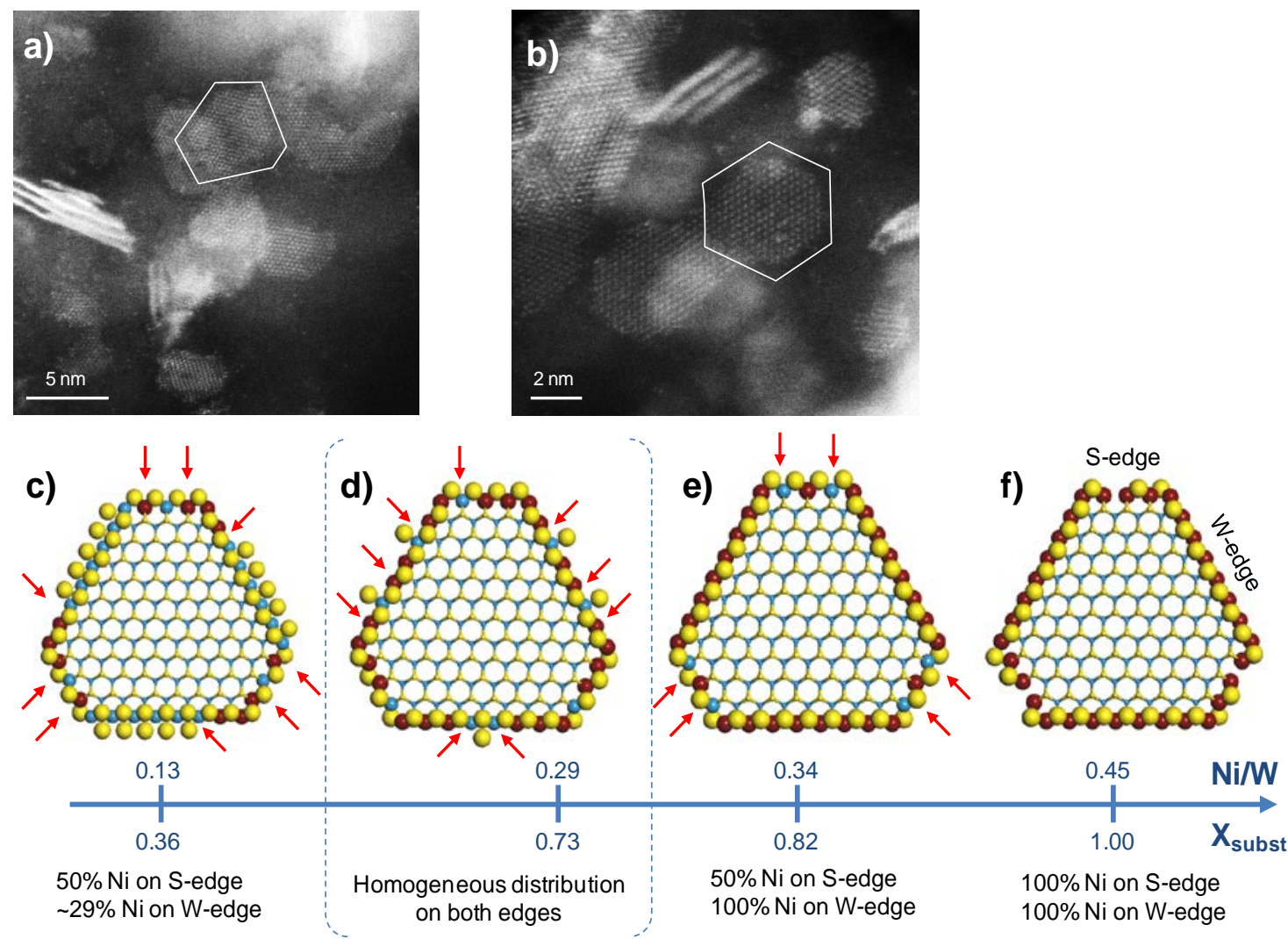

Fig. 2 HR- HAADF-STEM micrographs of NiWS crystallites sulfided at $600^{\circ} \mathrm{C}\left(\mathrm{H}_{2} \mathrm{~S} / \mathrm{H}_{2}, 15 \mathrm{~mol} \% \mathrm{H}_{2} \mathrm{~S}\right)$ for $2 \mathrm{~h}$, with $1.7 \mathrm{~W} . \mathrm{nm}^{-2}$ and $\mathrm{Ni} / \mathrm{W}=0.2$. In each case, a crystallite oriented planar to the surface is surrounded by white lines for a better view (a, b). Molecular models of NiWS crystallites for various Ni/W ratio and Ni-to-W substitution ratio at the edge. (c, e, f). The local structures of the edges (including S-coverage) are consistent with the thermodynamically stable structures calculated by DFT[33] and morphology diagram reported in Figure S7. (d) Metastable edge structures exhibiting an homogeneous distribution of Ni-W mixed sites on both edges. A 
crystallite's structure with $7 \mathrm{~W}$ and $4 \mathrm{~S}$ atoms at the W-edge and S-edge, respectively, was chosen as a relevant molecular model according to TEM analysis (L 3.5 nm,). Mixed sites (if present) are indicated by red arrows. Dark red: nickel, Blue: tungsten, Yellow: sulfur.

We therefore look in greater details on how the Ni/W ratio can be associated to the $\mathrm{W}$ substitution by $\mathrm{Ni}$ at the edges. For that purpose, DFT calculations help us to unravel the atomic scale properties of the edge sites of NiWS nanocrystallites. Following the methodology defined earlier,[33] the calculated morphology diagram and the $\mathrm{Ni}$ edge distribution are reported in Figure S7. The various stable morphologies represented in Figures 2c, e, and f, are consistent with STEM observation whatever the Ni/W ratio and Ni-to-W substitution ratio at the edge. In particular, these three types of morphologies exhibiting different edge structures, are all energetically comparable in the sulfo-reductive conditions used here.

These crystallites exhibit different amounts of $\mathrm{Ni}$ atoms substituting $\mathrm{W}$ at the edges, corresponding to i) a partial substitution at both W- and S-edge (Figure 2c), ii) a partial substitution at the S-edge and a full substitution at the W-edge (Figure 2e), and iii) a full substitution at both edges (Figure 2f). These results highlight the possibility to generate active sites with various local environments: either Ni sites only (with tetrahedral or square planar structure) or mixed $\mathrm{Ni}-\mathrm{W}$ sites ( $\mathrm{Ni}$ in the close vicinity of $\mathrm{W}$ at edge). The distribution of $\mathrm{Ni}$ atoms on crystallite edges thus appears to be strongly dependent on sulfidation conditions and simultaneously on the preparation method. It should be noticed that Figure S7 shows that for lower sulfidation temperatures (higher chemical potentials of sulphur) as provided by the CSC method, Ni atoms can be stabilized more easily on both S- and M-edges. By contrast, too high sulfidation temperatures (more negative chemical potentials of sulphur) required for 
conventional samples may lead to the destabilization of $\mathrm{Ni}$ at edges. So an appropriate sulfidation temperature is expected to optimally decorate the edges of NiWS crystallites.

The combination of XPS and TEM analyses together with DFT results enables an accurate analysis of catalytic trends with respect to the distribution of Ni sites on the edges of the nanocrystallites. First, Ni/W ratio in the nanocrystallites, called (Ni/W) $)_{\text {slab_exp, }}$ and quantified by XPS analyses of NiWS after catalytic tests (Table S1), show that during catalytic test, the $(\mathrm{Ni} / \mathrm{W})_{\text {slab_exp }}$ tends to slightly diminish for almost all catalysts, and highlights a probable reorganization of surface species (NiWS and $\mathrm{Ni}_{\mathrm{x}} \mathrm{S}_{\mathrm{y}}$ ) under operating conditions. The theoretical $\mathrm{Ni} / \mathrm{W}$ ratio, $(\mathrm{Ni} / \mathrm{W})_{\text {slab_theo, }}$ is then systematically calculated using the different molecular models of NiWS crystallites (vide supra) and the TEM crystallites sizes. This allows us to determine the theoretical Ni-to-W substitution ratio on edges, $\mathrm{X}_{\text {subst_theo, }}$ as a function of the $(\mathrm{Ni} / \mathrm{W})_{\text {slab_theo }}$ and $(\mathrm{Ni} / \mathrm{W})_{\text {slab_exp }}($ Tables S4 and S5). For crystallites sizes ranging from 3.2 to $4.1 \mathrm{~nm}$ (i.e. close to what is observed by TEM) and (Ni/W) slab_theo between 0.36 and 0.49 , all $\mathrm{W}$ atoms on edges and corners are likely substituted by $\mathrm{Ni}$ $\left(\mathrm{X}_{\text {subst_theo }}=1.00\right.$, see Table S4 and Figure $\left.2 \mathrm{f}\right)$. This theoretical analysis is consistent with XPS analyses, showing that the highest $(\mathrm{Ni} / \mathrm{W})_{\text {slab_exp }}$ measured on spent CSC catalysts is 0.40 $( \pm 0.06)$ for $\mathrm{Ni} / \mathrm{W} \geq 0.44$. This value is also compatible with data on $\mathrm{Co}(\mathrm{Ni}) \mathrm{MoS}$ phases.[2-5] However, various CSC and conventional catalysts exhibit $0.12 \leq(\mathrm{Ni} / \mathrm{W})_{\text {slab_exp }} \leq 0.30$, thus highlighting partial substitution of $\mathrm{W}$ by $\mathrm{Ni}$ at the edges $\left(0.34 \leq \mathrm{X}_{\text {subst_exp }} \leq 0.79\right)$.

Figure 3a illustrates the relationship between $\mathrm{X}_{\text {subst }}$ and $(\mathrm{Ni} / \mathrm{W})_{\text {slab}}$, considering both theoretical and experimental data reported in Tables S4, S5 and S6, for the three types of thermodynamically stable particles (Figure 2). NiWS crystallites with partially decorated Sedge and partially or fully decorated W-edge, which are the most thermodynamically favourable, exhibit ( $\mathrm{Ni} / \mathrm{W})_{\text {slab_theo }}$ varying between 0.13 (Figure 2c) and 0.34 (Figure 2e). 


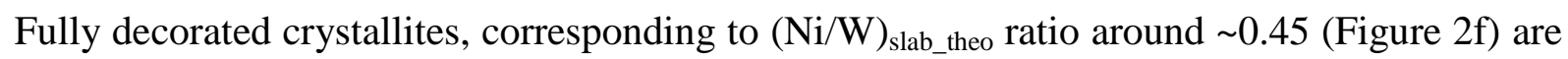
likely corresponding to the CSC catalysts with initial Ni/W above 0.44 . The catalyst prepared with $\mathrm{Ni}(\mathrm{acac})_{2}$ deposited on a conventional $\mathrm{W}$ precursor, which exhibits the lowest $(\mathrm{Ni} / \mathrm{W})_{\text {slab_exp }}(0.12)$ and $\mathrm{X}_{\text {subst_exp }}(0.35)$, probably contains crystallites represented in Figure 2c. In addition, we also plot the case of crystallites exhibiting an out of thermodynamic equilibrium Ni distribution at the edge (such as the one of Figure 2d). In particular, CSC catalyst with $\mathrm{Ni} / \mathrm{W}=0.21,(\mathrm{Ni} / \mathrm{W})_{\text {slab_exp }}=0.30$ and $\mathrm{X}_{\text {subst_exp }} \sim 0.79$ may contain such crystallites, where Ni-W mixed sites are more numerous on the $\mathrm{W}$-edge. The CSC preparation method thus allows for reaching a distribution of Ni site that is more homogeneous than the one expected from pure thermodynamic equilibrium calculated by DFT. The intimate interaction between molecular precursors of $\mathrm{Ni}$ and $\mathrm{W}$ during impregnation of CSC samples likely produces a NiWS phase with different types of mixed Ni-W sites at the edges, when compared to the conventional method. In addition, the use of a $\mathrm{W}$ molecular precursor, which undergoes sulfidation of $\mathrm{W}$ at much lower temperature,[2] probably leads to the more homogeneous incorporation of $\mathrm{Ni}$ at the edges which is known to be a limiting parameter with conventional preparation methods.[18,34] 

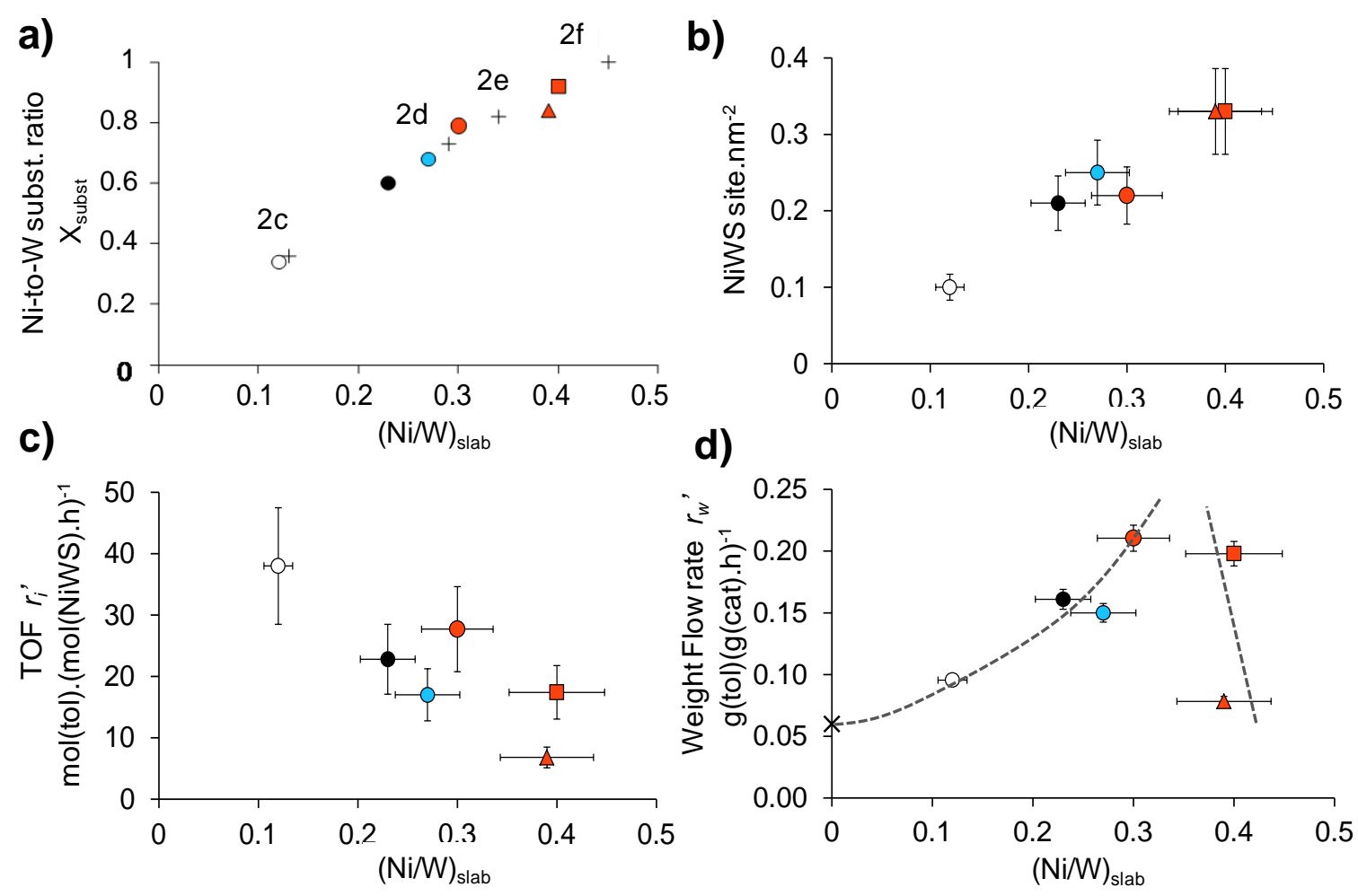

$$
\begin{aligned}
& \text { Theoretical model } \\
& \text { CSC, Ni/W }=1.00 \\
& \text { CSC, Ni/M }=0.44 \\
& \text { CSC, Ni/W }=0.21
\end{aligned}
$$

Conv. Calc. , $\mathrm{Ni} / \mathrm{W}=0.22$

Conv. Dried, Ni/W $=0.22$

Ni(acac) ${ }_{2}$ over $\mathrm{WO}_{\mathrm{x}}$ (conv.), $\mathrm{Ni} / \mathrm{W}=0.22$

Fig. 3 a) Ni-to-W substitution atomic ratio $\left(\mathrm{X}_{\text {subst }}\right)$ as a function of Ni-to-W atomic ratio in the NiWS slabs $\left((\mathrm{Ni} / \mathrm{W})_{\text {slab }}\right)$. Theoretical data deduced from DFT morphology models with TEM sizes (+): labels correspond to morphological models of Figure 2. Experimental data deduced from XPS and TEM (triangle, square, circles). b) Number of NiWS sites per $\mathrm{nm}^{2}$, c) TOF $\left(\mathrm{r}_{\mathrm{i}}{ }^{\prime}\right)$ of HYD and d) weight flow rate of toluene converted as a function of the Ni-to-W ratio in NiWS crystallites of catalysts and for various preparation methods.

As expected, greater values of $(\mathrm{Ni} / \mathrm{W})_{\text {slab }}$ correlates with the increase of surface concentration of NiWS sites (Figure 3b). Nevertheless, Figure 3c shows that for the full set of catalysts synthesized here, the TOF $r_{i}{ }^{\prime}$, expressed in mol(tol).(mol(NiWS).h) ${ }^{-1}$, i.e. as a function of the total amount of $\mathrm{Ni}$ incorporated in a NiWS phase, decreases when the $(\mathrm{Ni} / \mathrm{W})_{\text {slab }}$ ratio in crystallites increases. To a certain extent, this trend is consistent with previous results obtained on CoMoS,[11,35] NiMoS,[11] and NiWS[15] using more conventional preparation 
methods (with or without organic additives). This means that a Ni site is intrinsically more active when it is surrounded by $\mathrm{W}$ atoms at the edge. Thus, the best compromise between "number of sites” and "intrinsic activity” should provide the highest activity per gram, as illustrated in Figure 3d.

Interestingly, two CSC catalysts, with initial $\mathrm{Ni} / \mathrm{W}$ ratio ranging from 0.21 to 0.44 , with $(\mathrm{Ni} / \mathrm{W})_{\text {slab }}$ about 0.30 and 0.40 respectively, are intrinsically more active than their conventional counterparts $(\mathrm{Ni} / \mathrm{W}=0.22)$ exhibiting slightly lower $(\mathrm{Ni} / \mathrm{W})_{\text {slab }}(0.23$ to 0.27$)$. The enhanced intrinsic activity of CSC samples can thus only be explained by a more homogeneous distribution of $\mathrm{Ni}$ and $\mathrm{W}$ sites at both $\mathrm{W}$ - and S-edges induced by the CSC method (Figure 2d). When using conventional methods, the edge structures may be closer to the most stable structures reported either in Figure 2c or 2d (or a combination of both). Previous DFT study showed that toluene adsorption preferentially occurs on sites located on the Mo-edge of CoMoS.[10,35] Similarly, it is expected that toluene adsorption will be preferred on the W-edge for NiWS phases. As a consequence, enhancing the presence of $\mathrm{Ni}$ sites at the W-edge promotes higher catalytic activities, as for CSC samples with $\mathrm{Ni} / \mathrm{W}=0.21$. The further addition of $\mathrm{Ni}$ at the edges $(\mathrm{Ni} / \mathrm{W}=0.44)$ leads to a higher substitution level of edges (0.92, i.e. close to the full decoration), which becomes detrimental to the intrinsic activity. This result implies that Ni sites tend to be more active on partially decorated $\mathrm{W}$ - and S-edge than on fully decorated ones. Ni sites is thus assisted by vicinal W sites bearing -SH groups involved in the hydrogenation steps of toluene.[36] For $\mathrm{Ni} / \mathrm{W}=1.00$, the $(\mathrm{Ni} / \mathrm{W})_{\text {slab_exp }}$ ratio stays close to the value previously found for the sample with $\mathrm{Ni} / \mathrm{W}=0.44$ (i.e. 0.39 vs. 0.40). Although no significant change in the NiWS intrinsic activity was thus expected, a dramatic drop of activity is observed, probably originating from the presence of higher amounts of the $\mathrm{Ni}_{\mathrm{x}} \mathrm{S}_{\mathrm{y}}$ phase, which is suspected to inhibit the accessibility to NiWS active 
sites. As a consequence, the right balance between the intrinsic activity and the amount of active sites is reached for the CSC catalyst with $(\mathrm{Ni} / \mathrm{W})_{\text {slab }}$ ratio close to 0.3 , which leads to the highest catalytic conversion among all catalysts (Figure 3d).

\section{Conclusion}

By using a molecular approach - controlled surface chemistry (CSC) method - we prepared highly active amorphous silica-alumina (ASA)-supported NiWS catalysts, which were fully characterized by combining IR, XPS, TEM, HR-HAADF-STEM and DFT calculations. The origins of the enhanced catalytic activity in toluene hydrogenation can be found in the following physico-chemical properties of the NiWS active phase at the different stages of the preparation and activation:

$1 /$ the controlled grafting of $\mathrm{Ni}$ and $\mathrm{W}$ molecular precursors on the ASA surface, as highlighted by IR spectroscopy,

2/ the higher amount of $\mathrm{W}$ sulfide generated at a lower sulfidation temperature allows for an improved $\mathrm{Ni}$ promoter insertion in $\mathrm{WS}_{2}$ slabs during sulfidation. According to DFT calculations, the sulfidation temperature directly impacts the amount of $\mathrm{Ni}$ present at the edges.

3/ the distribution of $\mathrm{Ni}$ at the edges of the $\mathrm{WS}_{2}$ crystallites is more homogeneous than in conventional catalysts, as quantified by XPS, STEM-HAADF and DFT based morphological models.

Such an improved - homogeneous - distribution of $\mathrm{Ni}$ sites at the edges of NiWS nanocrystallites provides an optimal balance between the amount of active sites and their intrinsic hydrogenating activity. In particular, toluene hydrogenation activity increases when crystallites are partially decorated on both $\mathrm{W}$ - and S-edges for $(\mathrm{Ni} / \mathrm{W})_{\text {slab }}$ ratio close to 0.3 , 
which is achieved by the use of the CSC preparation method and the highly active W-ethoxy precursor. For higher $\mathrm{Ni} / \mathrm{W}$ ratio, the formation of $\mathrm{Ni}_{\mathrm{x}} \mathrm{S}_{\mathrm{y}}$ may also blocks the access of active sites. Hopefully, this work opens new route towards the preparation more active NiWS catalysts. Further work is currently underway to explore the potential of this approach towards the optimization of HDS catalysts.

\section{References}

[1] H. Toulhoat, P. Raybaud, Catalysis by Transition Metal Sulphides: From Molecular Theory to Industrial Application, Technip, Paris, France, 2013.

[2] T. Alphazan, A. Bonduelle-Skrzypczak, C. Legens, A.-S. Gay, Z. Boudene, M. Girleanu, O. Ersen, C. Copéret, P. Raybaud, ACS Catal. 4 (2014) 4320.

[3] Y.I. Yermakov, Stud. Surf. Sci. Catal. 7 (1981) A57.

[4] C. Copéret, A. Comas-Vives, M.P. Conley, D.P. Estes, A. Fedorov, V. Mougel, H. Nagae, F. Núñez-Zarur, P.A. Zhizhko, Chem. Rev. 116 (2016) 323.

[5] N. Popoff, E. Mazoyer, J. Pelletier, R.M. Gauvin, M. Taoufik, Chem. Soc. Rev. 42 (2013) 9035.

[6] S.L. Wegener, T.J. Marks, P.C. Stair, Acc. Chem. Res. 45 (2012) 206.

[7] C. Copéret, M. Chabanas, R. Petroff Saint-Arroman, J.-M. Basset, Angew. Chem. Int. Ed. 42 (2003) 156.

[8] Y.I. Yermakov, A.N. Startsev, V.A. Burmistrov, Appl. Catal. 11 (1984) 1.

[9] T. Halbert, T.C. Ho, E.I. Stiefel, R.R. Chianelli, M. Daage, J. Catal. 130 (1991) 116.

[10] A.D. Gandubert, E. Krebs, C. Legens, D. Costa, D. Guillaume, P. Raybaud, Catal. Today 130 (2008) 149. 
[11] K. Marchand, C. Legens, D. Guillaume, P. Raybaud, Oil Gas Sci. Technol. - Rev IFP 64 (2009) 719.

[12] G. Magendie, B. Guichard, D. Espinat, Catal. Today 258 (2015) 304.

[13] E. Krebs, B. Silvi, P. Raybaud, Catal. Today 130 (2008) 160.

[14] M. Sun, A.E. Nelson, J. Adjaye, J. Catal. 226 (2004) 41.

[15] P.P. Minaev, P.A. Nikulshin, M.S. Kulikova, A.A. Pimerzin, V.M. Kogan, Appl. Catal. Gen. 505 (2015) 456.

[16] P. Moses, B. Hinnemann, H. Topsoe, J. Norskov, J. Catal. 248 (2007) 188.

[17] A. Stanislaus, B.H. Cooper, Catal. Rev. 36 (1994) 75.

[18] E.J.M. Hensen, Y. van der Meer, J.A.R. van Veen, J.W. Niemantsverdriet, Appl. Catal. Gen. 322 (2007) 16.

[19] E. Schachtl, L. Zhong, E. Kondratieva, J. Hein, O.Y. Gutiérrez, A. Jentys, J.A. Lercher, ChemCatChem 7 (2015) 4118.

[20] H. Topsøe , B. S. Clausen, R. Candia, C. Wivel, S. Mørup J. Catal. 68 (1981) 433.

[21] K.B. Tayeb, C. Lamonier, C. Lancelot, M. Fournier, A. Bonduelle-Skrzypczak, F. Bertoncini, Catal. Lett. 144 (2014) 460.

[22] D. Zuo, D. Li, H. Nie, Y. Shi, M. Lacroix, M. Vrinat, J. Mol. Catal. A: Chem. 211 (2004) 179.

[23] L. Coulier, G. Kishan, J.A.R. van Veen, J.W. Niemantsverdriet, J. Phys. Chem. B 106 (2002) 5897.

[24] M.J. Vissenberg, Y. van der Meer, E.J.M. Hensen, V.H.J. de Beer, A.M. van der Kraan, R.A. van Santen, J.A.R. van Veen, J. Catal. 198 (2001) 151.

[25] M. Sun, T. Bürgi, R. Cattaneo, D. van Langeveld, R. Prins, J. Catal. 201 (2001) 258.

[26] G.F. Hüttig, Discuss Faraday Soc 8 (1950) 215. 
[27] L. van Haandel, M. Bremmer, P.J. Kooyman, J.A.R. van Veen, T. Weber, E.J.M. Hensen, ACS Catal. (2015) 7276.

[28] F. Maugé, A. Vallet, J. Bachelier, J.C. Duchet, J.C. Lavalley, Catal. Lett. 2 (1989) 57.

[29] Y. Okamoto, K. Ochiai, M. Kawano, K. Kobayashi, T. Kubota, Appl. Catal. Gen. 226 (2002) 115.

[30] Y. Okamoto, A. Kato, Usman, K. Sato, I. Hiromitsu, T. Kubota, J. Catal. 233 (2005) 16.

[31] R. Molina, M.A. Centeno, G. Poncelet, J. Phys. Chem. B 103 (1999) 6036.

[32] V. Salinier, J.M. Corker, F. Lefebvre, F. Bayard, V. Dufaud, J.-M. Basset, Adv. Synth. Catal. 351 (2009) 2155.

[33] M. Girleanu, T. Alphazan, Z. Boudene, A. Bonduelle-Skrzypczak, C. Legens, A.-S. Gay, C. Copéret, O. Ersen, P. Raybaud, ChemCatChem 6 (2014) 1594.

[34] M. Breysse, M. Cattenot, T. Decamp, R. Frety, C. Gachet, M. Lacroix, C. Leclercq, L. de Mourgues, J.L. Portefaix, M. Vrinat, M. Houari, J. Grimblot, S. Kasztelan, J.P. Bonnelle, S. Housni, J. Bachelier, J.C. Duchet, Catal. Today 4 (1988) 39.

[35] V. Costa, B. Guichard, M. Digne, C. Legens, P. Lecour, K. Marchand, P. Raybaud, E. Krebs, C. Geantet, Catal. Sci. Technol. 3 (2013) 140.

[36] N. Guernalec, C. Geantet, T. Cseri, M. Vrinat, H. Toulhoat, P. Raybaud, Dalton Trans. 39 (2010) 8420. 